\title{
CORROSION BEHAVIORS OF LOW-CARBON STEEL IN COCOA BUTTER MEDIUM
}

\section{$\mathrm{MOMOH}, \mathrm{J} . \mathrm{J}$}

Department of Mechanical Engineering, Federal Polytechnic, Ado-Ekiti, Ekiti State, Nigeria.

\begin{abstract}
Investigations were carried out to examine critically the corrosion behavior using ASTM G1 and ASTM G31 standard procedure by examining the rate at which low-carbon steel will corrode in cocoa butter medium and how low-carbon steel pipe can be effectively used for production of storage and transportation device for cocoa butter during production process in industry. Cocoa butter was secured from Cocoa Product Company, Ile-Oluji, Ondo State while commercially available LowCarbon Steel was procured and cut into the coupons size with dimensions $(30.0 \times 20.0 \times 1.0) \mathrm{mm}^{3}$. The coupons were drilled at the top center with the use of pillar drilling machine of $1 \mathrm{~mm}$ diameter drill bit to suspend the coupons in the medium of exposure and some of the coupons were heat treated. Furthermore, the surfaces of the coupons were prepare for the corrosion test as prescribed in the ASTM G1 standard. Measured quantity of the medium of exposure which includes Cocoa Butter, Sodium Chloride solution, Seawater and dilute Hydrochloric Acid were used for the entire work. The result obtained were graphically presented and it was observed that Cocoa Butter is a good Corrosion inhibitor in the media of exposure as it form a barrier on the surfaces of the coupons in the exposure environment.
\end{abstract}

Keywords - Cocoa butter, ASTM G1, Low-Carbon Steel and Corrosion.

\section{INTRODUCTION}

Corrosion has always been regarded as costly problem to mitigate in any manufacturing, production and processing industries because of its pervasive nature and the best approach is to examine critically the corrosion behavior of metals being used in these industries so that an approximate method of forestalling its occurrence could be established. Low and medium carbon steels are known for their versatility in many of these processing industries. Cocoa and cassava processing industries are examples of industries that employ these steels for fabrication of various components of their machines (Afolabi, 2007). Furthermore, the occurrences of corrosion in any system that have contributed to loss of lives and properties, and at times attract spending huge amount as a

\author{
SHUAIB-BABATA, Y. L \\ Department of Materials and Metallurgical Eng, \\ University Of Ilorin, Ilorin, Nigeria
}

result of its effects have been revealed by different researchers [Aluko, 2004; Yasuo \& Toru, 1982; Evans, 1971].

Corrosion is degradation of materials' properties due to interactions with their environments, and corrosion of most metals is inevitable. The production of almost all metals involves adding energy to the system. As a result of this uphill thermodynamic struggle, the metal has a strong driving force to return to its native, low energy oxide state. This return to the native oxide state is what we call corrosion and even though it is inevitable, substantial corrosion control methods can be used to slow its progress toward the equilibrium state. Thus it is the rate of the approach to equilibrium that is often of interest. This rate is controlled not only by the nature of the metal surface, but also by the nature of the environment as well as the evolution of both. (Barbara and Robert, 2006)

Kaplinsky (2004) said, cocoa provides livelihoods for millions of people in over 50 countries in Africa, Latin America, the Caribbean and Asia. According to Oluwole and Olorunfemi (2009), at present, most of the cocoa beans are used in the production of cocoa products such as chocolate, cocoa powder (for drink, coloring and flavoring agents), chocolate syrup, and other product enrobed with chocolate. Cocoa beans, seeds of the Theobroma cocao L. tree are the primary raw material used for the preparation of cocoa, chocolate and other chocolate products, which are highly valued by consumers around the world (Joanna et al. 2015). The dominant constituent of cocoa bean is cocoa fat (50-57\%), called cocoa butter [Jahurul et al. 2013; Steinberg et al. 2003].

\section{MATERIALS AND METHOD}

Chemical Composition of the Specimen: The chemical composition of the low-carbon steel sample used for this corrosion test was analyzed using X-Ray Fluorescence (XRF) machine at Centre for Energy Research and Development, Obafemi Awolowo University, Ile-Ife, and the result are presented in Table 1

Table -1 Experiment Result

\begin{tabular}{|c|c|c|c|}
\hline Elements & Conc Value & Conc Error & Unit \\
\hline $\mathbf{T i}$ & 0.0300 & \pm 0.0013 & wt.\% \\
\hline $\mathbf{M n}$ & 0.8023 & \pm 0.0100 & wt.\% \\
\hline $\mathbf{C a}$ & 2.0261 & \pm 0.0904 & wt.\% \\
\hline $\mathbf{K}$ & 0.2700 & \pm 0.0000 & wt.\% \\
\hline $\mathbf{F e}$ & 96.2922 & \pm 0.0351 & wt.\% \\
\hline
\end{tabular}




\begin{tabular}{|c|c|c|c|}
\hline $\mathbf{Z n}$ & 0.0215 & \pm 0.0015 & wt.\% \\
\hline $\mathbf{C r}$ & 0.0637 & \pm 0.0024 & wt.\% \\
\hline $\mathbf{Z r}$ & 0.0126 & \pm 0.0015 & wt.\% \\
\hline $\mathbf{C o}$ & 0.0489 & \pm 0.0018 & wt.\% \\
\hline $\mathbf{C u}$ & 0.0125 & \pm 0.0012 & wt.\% \\
\hline $\mathbf{B r}$ & 0.0055 & \pm 0.0007 & wt.\% \\
\hline $\mathbf{Y}$ & 0.0031 & \pm 0.0007 & wt.\% \\
\hline Sc & 0.2316 & \pm 0.0113 & wt.\% \\
\hline $\mathbf{C}$ & 0.1800 & \pm 0.0100 & wt.\% \\
\hline
\end{tabular}

The density of the sample (low-carbon steel) used as given in the ASTM G1 standard is $7.86 \mathrm{~g} / \mathrm{cm}^{3}$

Preparation of Specimens (Surface): The samples were cut into coupons with dimensions $(30.0 \times 20.0 \times 1.0) \mathrm{mm}^{3}$ as shown in Figure 1.

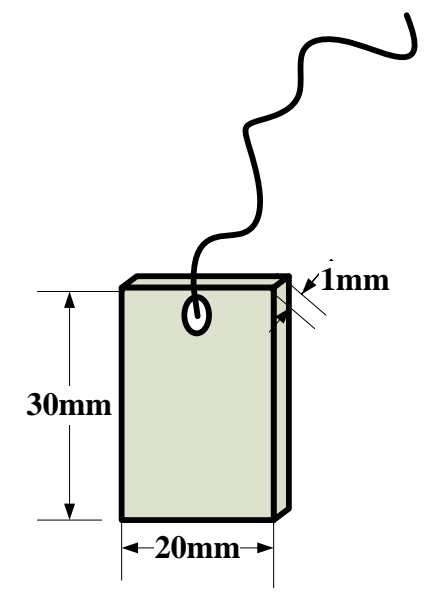

Figure 1: Samples cut into coupons

Coupon Preparation: It is desirable to mark specimens used in corrosion test with a unique designation during preparation, the specimens used for this corrosion test were marked appropriately. Several techniques may be used depending on the type of specimen and test. But for the case of this study, the method used is described as Stamping by writing the name of each specimen on a cardboard and attached to them by a rope.

Surface Finish: For more searching tests of either the metal or the environment, standard surface finishes were used. For the interest of this study, the procedure for surface finish of the specimens is as described as follows:

a.) Degreasing: - The corrosion specimens were degreased (i.e removing the grease which was used to prevent them from corroding) in an organic solvent (Benzene).

b.) Abrading: - After the specimens have been degreased in benzene, the edges as well as the faces of the specimens were abraded with a slurry of an appropriate abrasive paper.

After this two steps were completed, all the specimens were rinsed thoroughly, hot air dry with a hand hot air drier and stored in desiccators. Meanwhile, the cleaned, dried specimens were measured and weighed. Their dimensions were measured to be $30 \mathrm{~mm} \times 20 \mathrm{~mm} \times 1 \mathrm{~mm}$ and mass determined to the three significant figure using a weighing machine.

c) Etching: - The specimens were etched in 5\% hydrochloric acid for 1 minute to remove the abraded particles from the surface of the metal sample, it was then rinsed thoroughly in distilled water for another 1 minute and hot air dry by a hand hot air drier.

Laboratory Extraction of Cocoa Butter: The cocoa beans were washed in cold water to remove the dirt and residue, all immature beans were separated and the good once were placed in a clean cloth to dry. The electric roaster oven was turned on and was preheated to a temperature between $280^{\circ}$ and $320^{\circ}$. The cocoa beans were now put in the roaster for 8 minutes. After this minutes of roasting, the beans were removed from the roaster and allowed to cool on a wire rack until they reach an average temperature of $90^{\circ}$. The beans were placed into small groups, based on their size.

Furthermore, the oven was preheated to $200^{\circ}$ and the hulls of the cocoa beans were broken into small pieces by hitting them with the kitchen mallet. The beans that were freed of the hulls were placed on a cookie sheet and it was insert into the oven for 15 minutes. The heated beans were put in a coffee grinder and grinded until cocoa liquor was obtained. This then was strained through a cotton cloth to obtain the coca butter oil. Average cocoa beans analysis is presented in Table 2

Table -2 Experiment Result

\begin{tabular}{|c|c|c|c|}
\hline Properties & $\begin{array}{c}\text { Cocoa } \\
\text { beans }\end{array}$ & $\begin{array}{c}\text { Cocoa } \\
\text { butter }\end{array}$ & $\begin{array}{c}\text { Dark } \\
\text { chocolate }\end{array}$ \\
\hline Proteins & 18.0 & 6.4 & 6.0 \\
\hline Lipids & 56.0 & 54.0 & 27.0 \\
\hline Carbohydrates & 13.5 & 28.0 & 54.0 \\
\hline Water & 3.0 & 2.0 & 1.0 \\
\hline Theobromine & 1.45 & 1.1 & 0.5 \\
\hline Caffeine & 0.05 & 0.5 & 0.07 \\
\hline Theophylline & - & - & 0.001 \\
\hline
\end{tabular}

Source: Hesse, (2002)

Corrosion Medium: The different medium of exposure used for the study are 100\% Cocoa Butter (CB), 100\% Distilled Water, 3\% CB plus Seawater, 1\% CB plus Seawater, 1\% CB plus Hydrochloric acid, 3\% CB plus Hydrochloric acid, 1\% CB plus Distilled Water, and 3\% CB plus Distilled Water, simulated seawater $(3 \% \mathrm{NaCl})$.

Exposure: Before exposing the coupons to the corrosion media as shown in Figures 2 and 3, the following heat treatment operation were carried out (Annealing, Normalizing, Quenching and Tempering) on different specimen and the microstructure of each coupon were obtained for each of the heat treated sample shown in Figure 4-8. After the heat treatment operation has been done and the microstructure of each coupon has been obtained, the metal coupons were immersed into the various test media mentioned. After the immersion period, the cleaning of the samples were carried 
International Journal of Engineering Applied Sciences and Technology, 2019

Vol. 4, Issue 3, ISSN No. 2455-2143, Pages 425-431

Published Online July 2019 in IJEAST (http://www.ijeast.com)

out and the corrosion rates were calculated as per ASTM G1 standard.

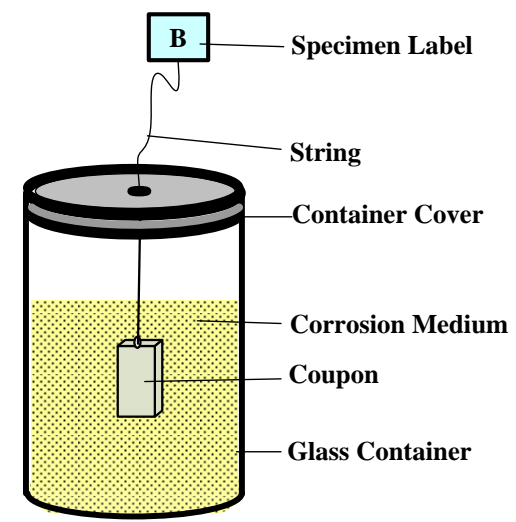

Figure 2: Experimental set-up showing immersion of steel samples in corrosion media

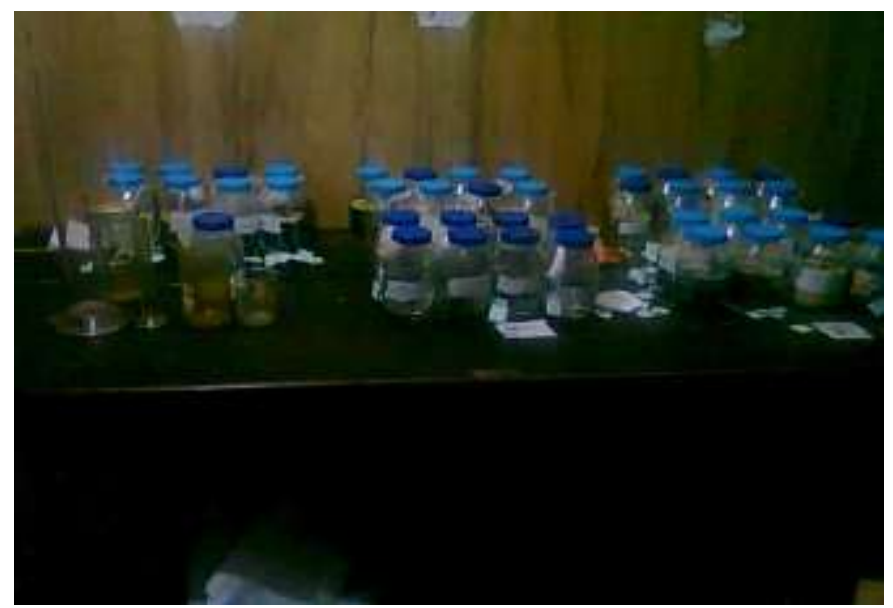

Figure 3: Samples exposed to different media

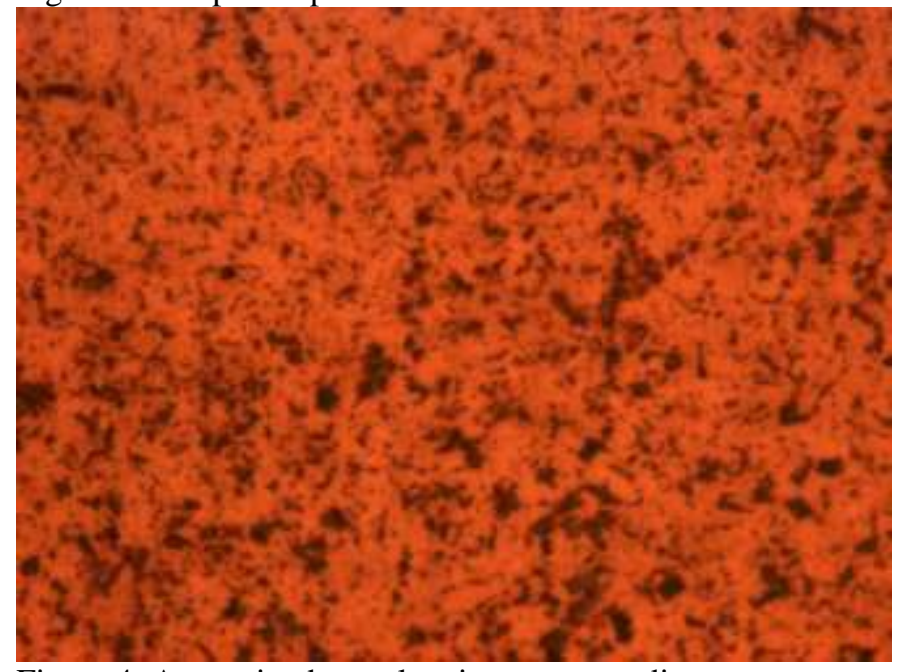

Figure 4: As received sample microstructure diagram.

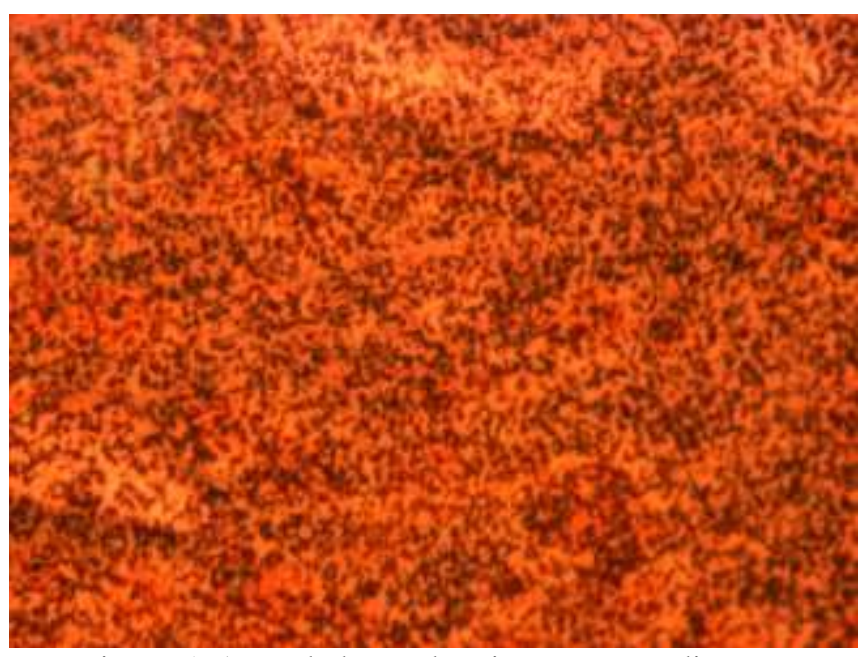

Figure 5: Annealed sample microstructure diagram

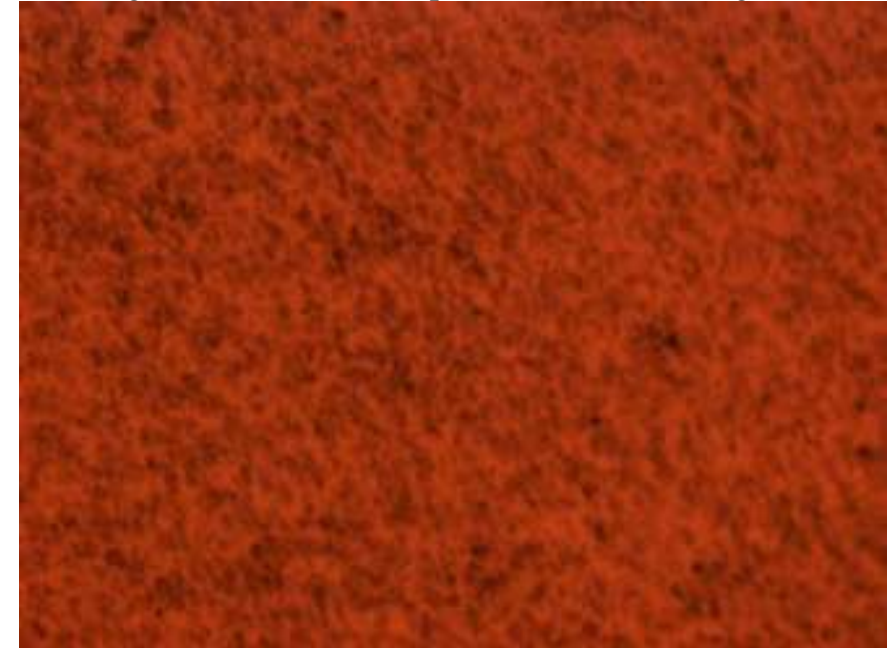

Figure 6: Normalized sample microstructure diagram.

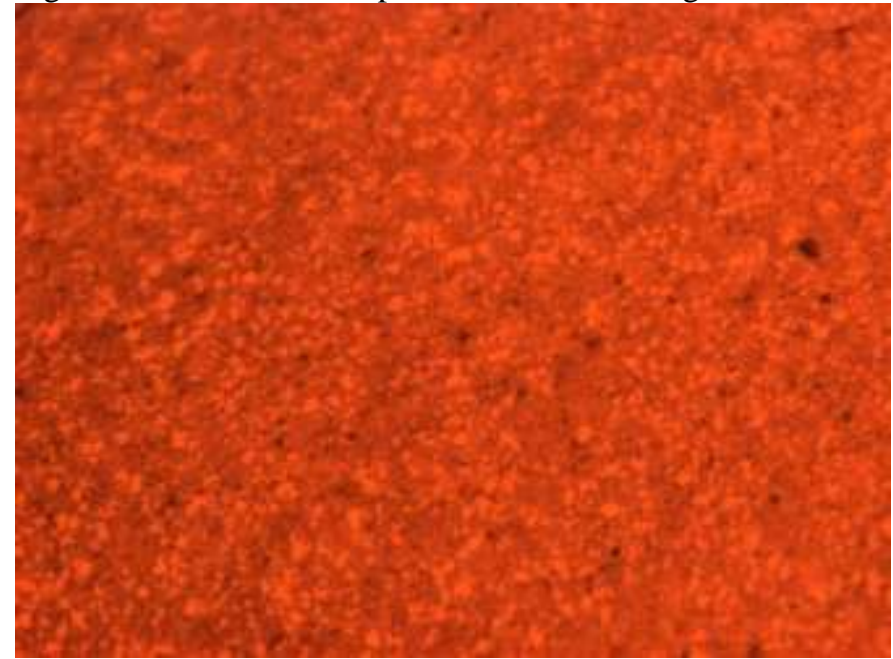

Figure 7: Quenched sample microstructure diagram. 
International Journal of Engineering Applied Sciences and Technology, 2019

Vol. 4, Issue 3, ISSN No. 2455-2143, Pages 425-431

Published Online July 2019 in IJEAST (http://www.ijeast.com)

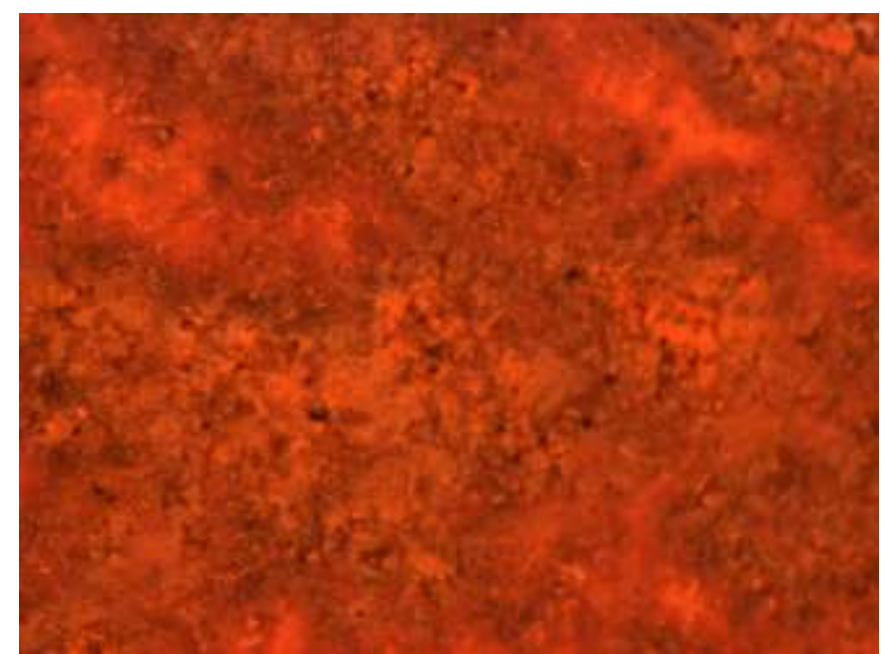

Figure 8: Tempered sample microstructure diagram.

\section{RESULTS AND DISCUSSION}

Mass-Loss Measurement: Many researchers use weight loss measurement method to determine the corrosion rate [Adebiyi et al. 2003; Oluwole et al. 2008; Sodile, 2002; Loto and Adesomo, 1998].The figures below show the variation in mass-loss of each of the samples of low-carbon steel in the absence and presence of different concentration of the cocoa butter as a function of time. The concentration of the cocoa butter varied from $1 \%-3 \%$, and the time of immersion was varied from 1-7 days at room temperature. From the results presented in Figures 9-16, it was observed that mass-loss of each of the samples increases with increase in immersion time but decreases with increase in concentration of cocoa butter. The increase in concentration of the cocoa butter increase the surface coverage on the metal and the adsorption of the phytochemical constituents on the metal surface hereby creating a barrier between the metal and the media of exposure. As received sample has the highest mass-loss, followed by normalized sample, annealed sample, Quenched sample and Tempered sample having the least mass-loss.

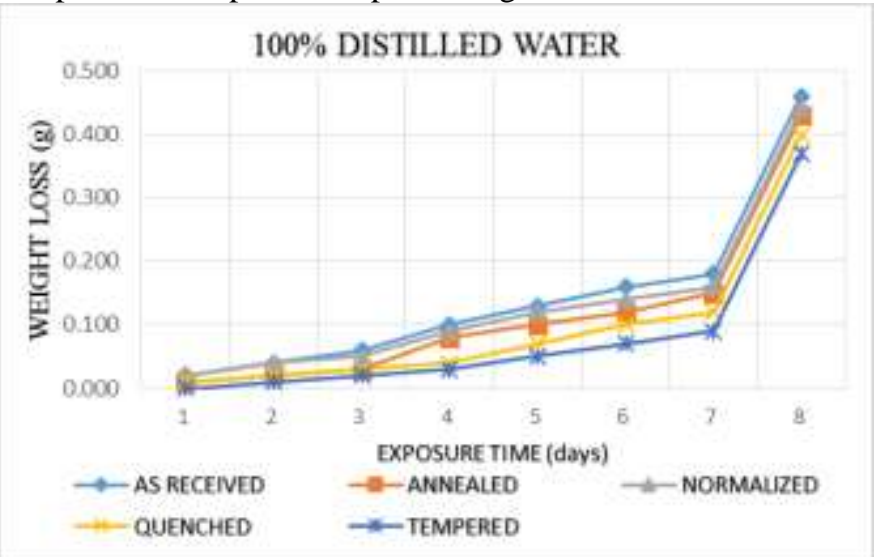

Figure 9: Graph of 100\% Distilled Water.

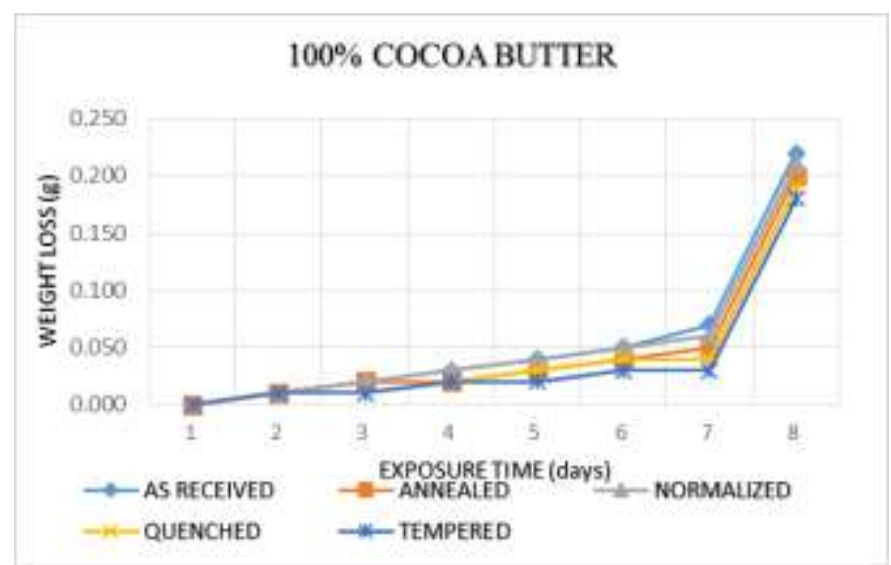

Figure 10: Graph of $100 \%$ Cocoa Butter.

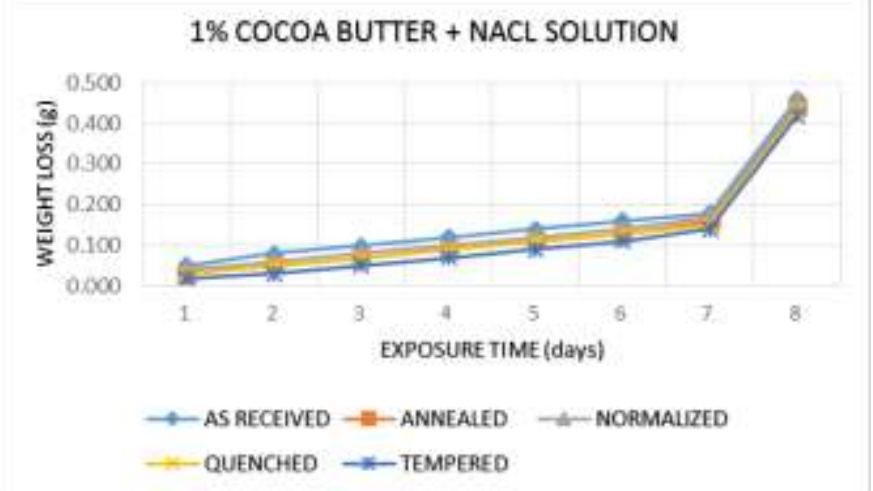

Figure 11: Graph of 1\% Cocoa Butter plus Sodium Chloride Solution.

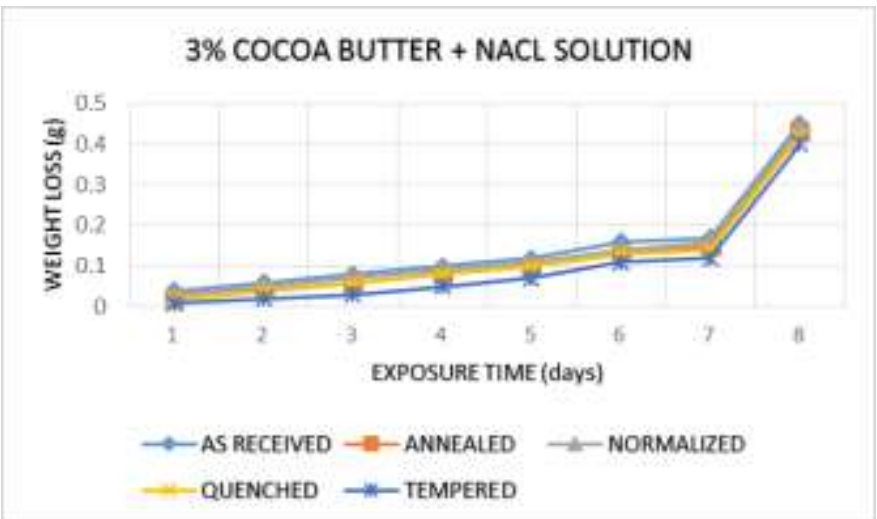

Figure 12: Graph of 3\% Cocoa Butter plus Sodium Chloride Solution 
International Journal of Engineering Applied Sciences and Technology, 2019

Vol. 4, Issue 3, ISSN No. 2455-2143, Pages 425-431

Published Online July 2019 in IJEAST (http://www.ijeast.com)

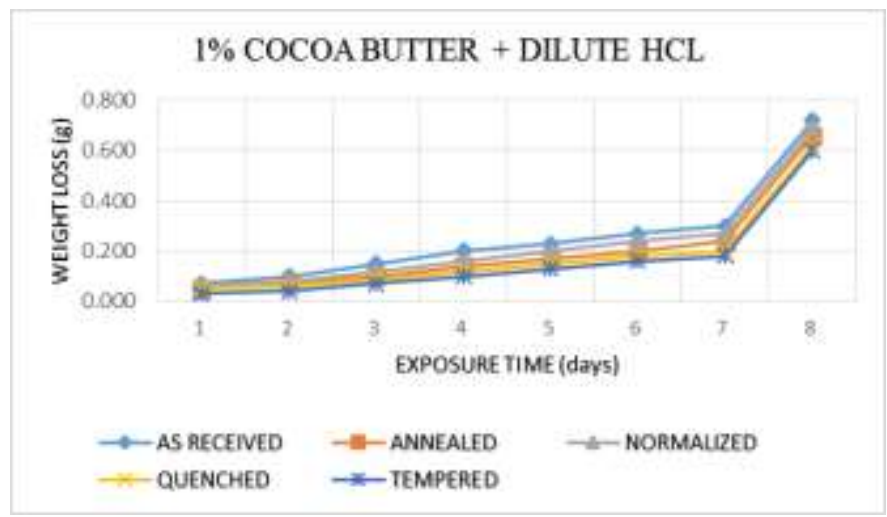

Figure 13: Graph of 1\% Cocoa Butter plus Dilute Hydrochloric Acid.

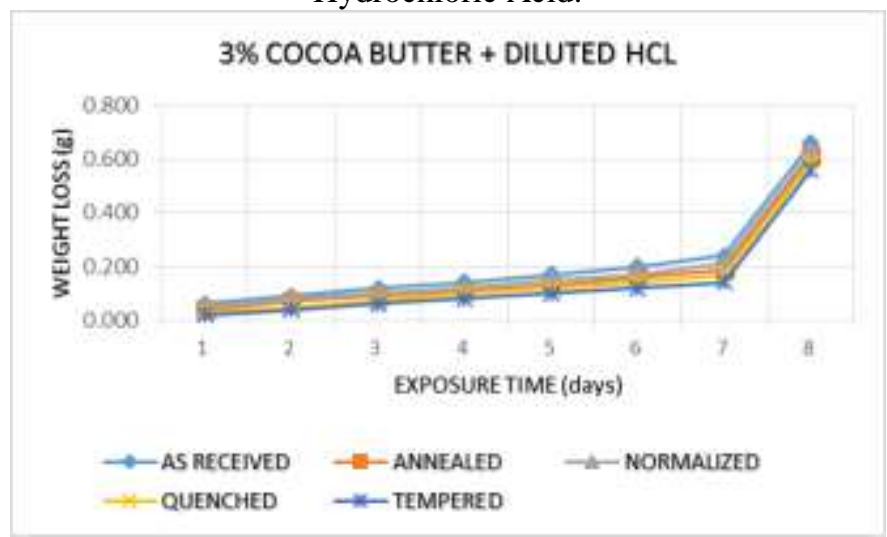

Figure 14: Graph of 3\% Cocoa Butter plus Dilute Hydrochloric Acid.

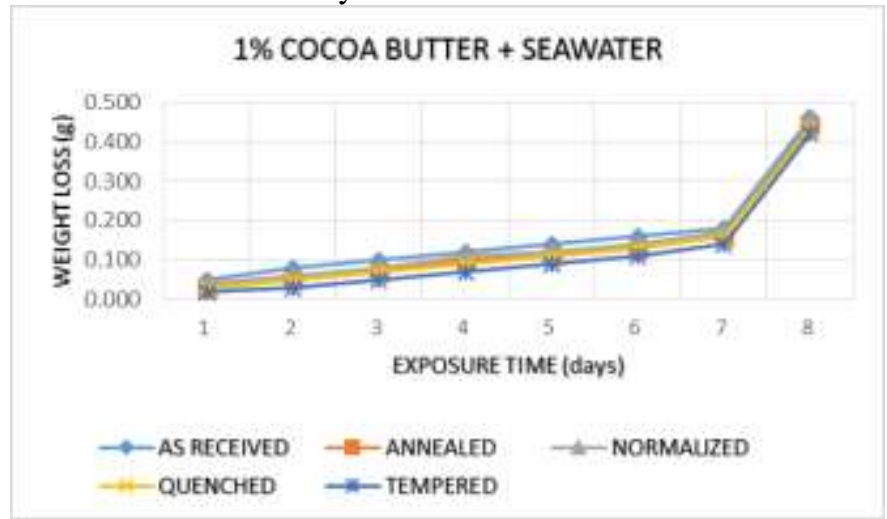

Figure 15: Graph of $1 \%$ Cocoa Butter plus Seawater

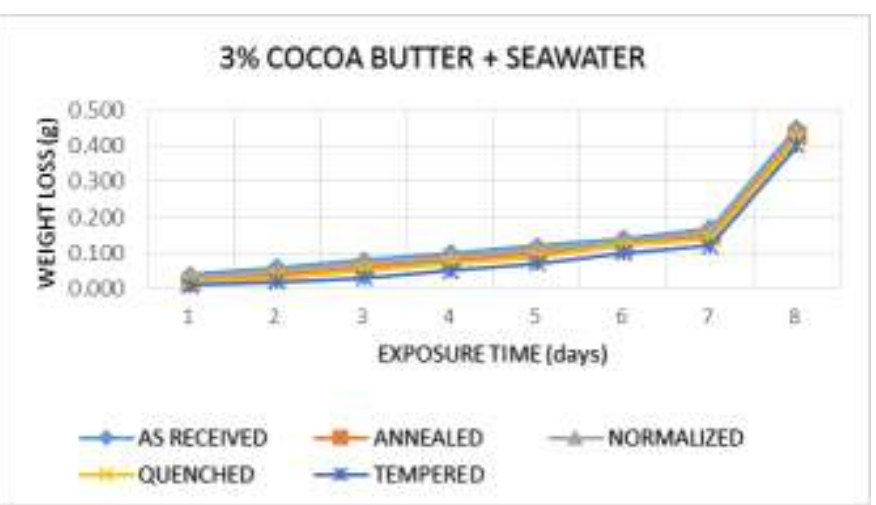

Figure 16: Graph of 3\% Cocoa Butter plus Seawater

Corrosion Rate Calculation: The corrosion rate of each of the samples used are calculated using the formula below as given in ASTM G1.

$$
\mathrm{C}_{\mathrm{R}}=\frac{\mathrm{K} \times \mathrm{W}}{\mathrm{A} \times \mathrm{T} \times \mathrm{D}}
$$

Where $\mathrm{K}=$ Corrosion rate constant (534)

$$
\begin{aligned}
& \mathrm{W}=\text { Mass-loss }(\mathrm{g}) \\
& \mathrm{A}=\text { Area of sample }(\mathrm{cm}) \\
& \mathrm{T}=\text { Time of exposure }(\mathrm{hrs}) \\
& \mathrm{D}=\text { Density of sample }\left(\mathrm{g} / \mathrm{cm}^{3}\right)
\end{aligned}
$$

The area of the sample was calculated with the formula given below

$$
\text { Area }=2(\mathrm{~h} \times \mathrm{b})+2(1 \times \mathrm{h})+2(1 \times \mathrm{b})
$$

Where

$\mathrm{h}=$ height $(\mathrm{cm}), \mathrm{b}=$ breadth $(\mathrm{cm}), \mathrm{l}=$ length $(\mathrm{cm})$

Visual Observation of the Coupons in the Exposure Media $100 \%$ cocoa butter: The color of this medium remains the same as far as this research work is concern. In the cause of the reaction between the coupons and the medium, the corrosion product settles at the base of the beaker with little concentration of the product on the surface of the coupons. The reaction does not involve the release of any gas, hence hydrogen damage type of corrosion took place since the medium contains $2 \%$ water.

$100 \%$ distill water: The first 10 minute of immersion, there was no any changes that occurred and this continue till about 3-4hours, but before 24hours of exposure, the medium changes slightly from its colorless nature to something that looks like brown color. After 24 hours, the brown color begin to manifest and it continues in this trend until it finally becomes brown color after 4days of immersion. Meanwhile, the surfaces of the coupons were changing alongside with the medium as the hours and days of immersion begin to increase. On the surfaces of the coupons, there was formation of corrosion product showing that uniform corrosion took place. Also, some of the product form sediments at the base of the beaker as the days of exposure increases.

$1 \%$ cocoa butter plus sodium chloride solution: For the very first few hours of immersion, there was no any recordable 
observation but after 24hours, it was observed that the coupons have changed and the corrosion product forms layer on the surfaces of the specimen while some were washed down to the base of the beaker forming sediments. The medium turns brown after 3 days of exposure.

3\% cocoa butter plus sodium chloride solution: The observation was just like that of $1 \%$ cocoa butter plus sodium chloride but it is just that the reaction was not as fast as that of $1 \%$ because of the decrease in the concentration of sodium chloride and increase in cocoa butter volume.

$1 \%$ cocoa butter plus dilute hydrochloric acid: Immediately the immersion took place, the reaction took place as gas was evolve in the form of bubbles from each of the surfaces of the coupons. Because of the release of bubbles, the corrosion particles could not adhere to the coupons surfaces but rather form sediments at the base of the beaker. After immersion, it was observed that each specimen has a gray color appearance. Hence, combined action corrosion took place.

3\% cocoa butter plus dilute hydrochloric acid: The same thing that happens in $1 \%$ cocoa butter plus dilute hydrochloric acid happened here but the reaction was not as fast as the former because of change in concentration.

$1 \%$ cocoa butter plus seawater: As it was known that seawater contains some amount of sodium chloride, so what was observed here is the same with what was observed in the $1 \%$ cocoa butter plus sodium chloride solution.

$3 \%$ cocoa butter plus seawater: As it was known that seawater contains some amount of sodium chloride, so what was observed here is the same with what was observed in the $3 \%$ cocoa butter plus sodium chloride solution.

\section{CONCLUSION}

Corrosion of metal is inevitable as long as they will be expose to various environment, therefore engineering materials should be properly protected to prevent them from corrosion in the environment they are exposed to. Studies have shown that natural products of plants origin e.g. Grape fruits juice contain different organic compounds (e.g. Alkaloids, tannins, pigments, organic and amino acids) and most are known to have inhibitive action.[ Abiola, O. K. and Oforka, 2002; Saleh et al. 1980]. Also, inhibitor such as cocoa butter can be used to fight against corrosion both in acid and alkaline medium. Hence, one can conclude that cocoa butter can inhibit the corrosion rate of metal in acidic environment.

\section{RECOMMENDATION}

It is recommend that, fabricators of storage containers should always use mild steel that is heat treated for the fabrication and construction of storage containers because treated mild steel does not easily corrode and when coated the can stand the test of time and this is more economical for any industrial set-up.

\section{REFERENCE}

Abiola, O. K. and Oforka, N. C. (2002). Inhibition of the Corrosion of Mild Steel in Hydrochloric Acid by (4-Amino - 2 -Methyl-5-Pyrimidinyl Methylthio) Acetic Acid and its Precursor, Journal of Corrosion Science and Engineering Volume 3, Paper 21, http://www.jcse.org/volume3/paper21/v3p21.php?co mmentmode $=2$

Adebiyi, K.A., Hammed, K.A., and Ajayi, E.O. (2003). "Predictive Model for Evaluating Corrosion Rate of Mild Steel inSix Environments". LAUTECH Journal of Engineering and Technology. In: Jekayinfa, S.O.(ed). Effect of Cassava Fluid on Corrosion Performance of Mild Steel. 52(5): 286-292.

Afolabi, A. S. (2007) "Corrosion and Stress Corrosion Behaviors of Low and Medium Carbon Steels in Agro-Fluid Media" Leonardo Electronic Journal of Practices and Technologies, Issue 10, p. 55-66. http://lejpt.academicdirect.org/A10/055_066.htm

Aluko, F. I. (2004), "The Effect of Heat Treatment on the Microstructure of grey Cast Iron in Paper Making Industries", Nigrian Journal of Engineering Management, Vol. 5, No. 2, pp.9

ASTM Standard G1, "Standard Practice for Laboratory Immersion Corrosion Testing of Metals".

ASTM Standard G31, "Standard Practice for Laboratory Immersion Corrosion Testing of Metals".

Barbara, A. S. and Robert, G. K., (2006). "The Electrochemical Society Interface".

Evans, U. R. (1971), "The corrosion and Oxidation of Metal: Scientific Principles and Practical Applications", Edward Arnold Publishers Ltd., London.

Jahurul, M. H. A, Zaidul, I. S. M, Norulaini, N. A. N, Sahena, F, Jinap, S, Azmir J, Sharif, K. M, and Mohd Omar A. K, (2013). "Cocoa Butter Fats and Possibilities of Substitution in Food Products Concerning Cocoa Varieties, Alternative Sources, Extraction Methods, Composition, and Characteristics". Journal of Food Engineering, $\quad$ pp 467- 476. http://jakraya.com/journal/pdf/2-jbetArticle_1.pdf

Joanna, O, Dorota, Ż, Grażyna, B and Ewa N. (2015). “Cocoa Butter Alternative Fats" Plant Lipids Science, Technology, Nutritional Value and Benefits to Human Health, Research Signpost, pp 87-106 https://www.trnres.com/ebook/uploads/budrynconten t/T_1427784139Budryn\%202.4.pdf

Loto, C.A. and Adesomo, M.A. (1988). "The Corrosion of Mild Steel in Maize Juice, Acidified Maize Juice and 
Acetic Acid Environment". African Journal of Science and Technology Series A. 7(1).

Oluwole, O. O and Olorunfemi, O. (2009). "Corrosion Behavior of Nickel Plated Medium Carbon Steel in Cocoa Liquor" The Pacific Journal of Science and Technology, Volume 10. Number 2 pp $172-177$. http://www.akamaiuniversity.us/PJST10_2_172.pdf

Oluwole, O. O, Oloruntoba, D. T and Awheme, O. (2008). "Effect of Zinc Plating of Low Carbon Steel on Corrosion Resistance in Cocoa Fluid Environment". Materials and Design, 29(6):1266-1274. https://eurekamag.com/research/066/209/066209921. php

Saleh R. M, Ismail A.A. and ElHosary A.A, (1980). "Corrosion Inhibition by naturally occurring substances", British Corrosion Journal, 17, p.131. https://www.tandfonline.com/doi/abs/10.1179/00070 5982798274345

Sodile, J.L. 2002. "The Effect of Surface Finish on the Corrosion Rate of Steel". Nigerian Journal of Engineering Research and Development. 1(2): 1-9.

Steinberg, F. M, Bearden, M. M, and Keen, C. L, (2003) Cocoa and Chocolate Flavonoids: Implications for Cardiovascular Health. Journal of the Academy of Nutrition and Dietetics 103: 215-223. https://doi.org/10.1053/jada.2003.50028

Yasuo K. \& Toru M (1982) “Outline Proof Test Program for Heat Affected Zone of Welded Components (BWR), Predictive Methods of Assessing Corrosion Damage to BWR Piping and PWR Steam Generators", NACE Publication, Houston, pp 218 - 213. 